\begin{tabular}{|c|c|c|}
\hline & Int.J.Curr.Microbiol.App.Sci (2016) 5(8): 305-308 & \multirow{4}{*}{ 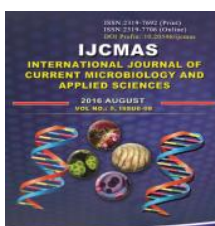 } \\
\hline & International Journal of Current Microbiology and Applied Sciences & \\
\hline & ISSN: 2319-7706 Volume 5 Number 8 (2016) pp. 305-308 & \\
\hline $\begin{array}{l}\text { EXCELLENT } \\
\text { PUBLISHERS }\end{array}$ & & \\
\hline PUBLISH & & \\
\hline
\end{tabular}

Original Research Article

http://dx.doi.org/10.20546/ijcmas.2016.508.032

\title{
A Comparative Evaluation of Microbiological versus Histopathological Diagnostic Methods for Helicobacter pylori Infection
}

\author{
R. Deepa ${ }^{1}$, Sujatha Varadarajan ${ }^{2}$, T.S. Vijayalakshmi ${ }^{3}$ and B. Natesan ${ }^{1}$ \\ ${ }^{1}$ Department of Microbiology, Institute of Microbiology, Madras Medical College and \\ RGGGH, Chennai-3, India \\ ${ }^{2}$ King Institute of Preventive Medicine, Chennai, Tamilnadu 600032, India \\ ${ }^{3}$ Department of Microbiology, Karpagavinayaga Institute of Medical Sciences, Kanchipuram, \\ Tamilnadu 603308, India \\ *Corresponding author
}

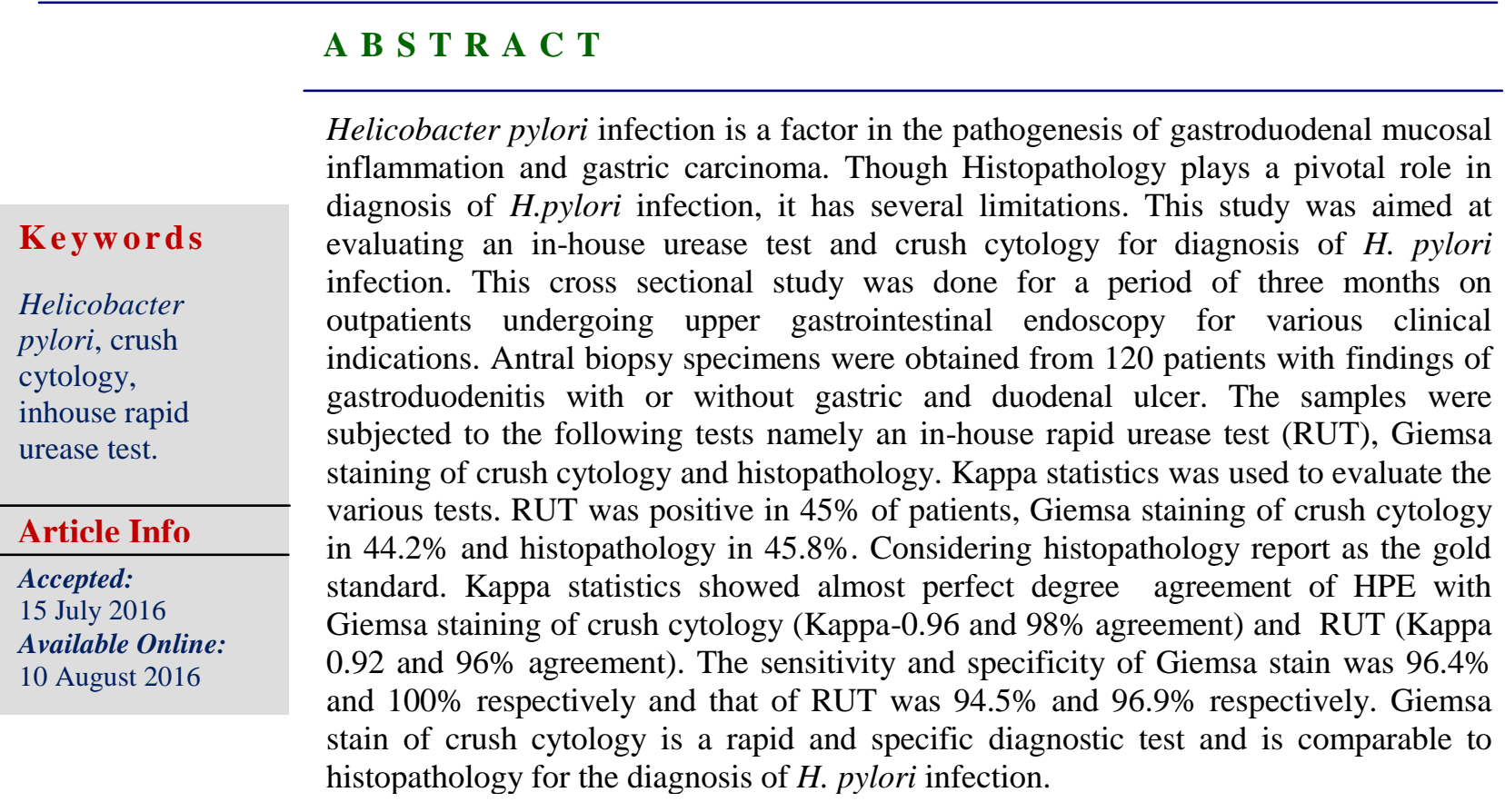

\section{Introduction}

Since its discovery in 1982 by Barry J. Marshall and J. Robert Warren from the gastric epithelium, Helicobacter pylori has been detected in every human population studied and is associated with inflammation of gastroduodenal mucosa. H.pylori is a gram negative helical bacterium which can be seen Haematoxylin \& Eosin stain $(\mathrm{H} \& \mathrm{E})$, the sensitivity and specificity of which has been reported as $69-93 \%$ and $89-90 \%$ respectively. Though HPE has the added advantage byits ability to detect the associated pathology, it has several limitations such as higher cost, longer turnaround time, interobserver variations etc. (Lee et al., 2015).

The aim of the study was to evaluate the Giemsa stained crush cytology and in-house rapid test with histopathological examination. 


\section{Materials and Methods}

Study design and population: This cross sectional study was done over a period of three monthson new out patients attending the endoscopy clinic with clinical indications for upper gastrointestinal endoscopy such as dyspepsia ,upper abdominal pain, vomiting .Patient's consent and Institutional Ethics Committee clearance were obtained.

Inclusion criteria: Patients with endoscopic findings of gastroduodenitis with or without gastric or duodenal ulcer were included.

Exclusion criteria: Patients with active bleeding ulcer (Lee et al., 2000), postgastrectomy, recent treatment with proton pump inhibitors or bismuth or Helicobacter pylori eradication therapy in the past one month were excluded.

Sample size: 120 patients

\section{Specimen collection and transport}

Biopsy specimens were obtained using a flexible gastroduodenoscope which was thoroughly rinsed with water and disinfected with $2 \%$ gluteraldehyde for ten minutes after each use. The biopsy forceps was cleaned and rinsed in $70 \%$ ethanol between each sample collection. Three biopsy specimens were taken from within $3 \mathrm{~cm}$ from the pylorus.

One bit was inoculated into urea broth. The other bits were transported in sterile screw capped vials containing isotonic salineand $10 \%$ formalin for crush cytology and histopathological examination respectively.

\section{Rapid Urease Test (Chiu et al., 1999):}

Inhouse rapid urease broth was prepared as follows.
Stock solution A (1 \% phenol red solution)

$1 \mathrm{gm}$ phenol red was dissolved in $32.5 \mathrm{ml}$ of $0.1 \mathrm{~mol} / \mathrm{L}$ sodium hydroxide and made upto $100 \mathrm{ml}$ with distilled water. The solution was autoclaved for 15 minutes at $121^{\circ} \mathrm{C}$.

Stock solution B (10\% urease solution)

$10 \mathrm{gm}$ of urea was dissolved in $100 \mathrm{ml}$ of sterile distilled water taking aseptic precautions. The $\mathrm{pH}$ of the solution was adjusted to 6.8 and dispensed on $0.5 \mathrm{ml}$ aliquots in sterile vials. Two drops of phenol red was added to each vial containing $0.5 \mathrm{ml}$ of $10 \%$ urea solution. A change in colour to pink within 30 minutes was interpreted as positive.

Crush cytology and staining (Nijhavan $\boldsymbol{e t}$ al., 1993; Soltesz et al., 1992)

One of the two specimens in the transport medium was crushed between sterile frosted glass slides, air dried, fixed with methanol and stained with Giemsa stain for 5 minutes and washed (Qualigenes, India). The smear was examined for deep purple bacilli with typical helical morphology.

\section{Histopathology (Barthel et al., 1990)}

The antral samples were sent to the Histopathology laboratory for further processing and Haematoxylin and Eosin staining.

\section{Results and Discussion}

The study population consisted of 120 adults with males and females in the ratio 19:5 in the age range of 20-70 years. The endoscopic findings included gastritis/duodenitisin 51 patients $(42.5 \%)$,gastric ulcer in 31 patients (25.8\%) and duodenal ulcer in 38 patients $(31.7 \%)$. 
Table.1 Results of Inhouse RUT and Giemsa stained crush cytology

\begin{tabular}{|l|c|c|c|}
\hline \multirow{2}{*}{ Test evaluated } & HPE & \\
\cline { 3 - 4 } & & + & - \\
\hline Giemsa stain & + & 53 & 65 \\
\cline { 2 - 4 } & - & 2 & 2 \\
\hline \multirow{2}{*}{ Inhouse RUT } & + & 52 & 63 \\
\cline { 2 - 4 } & - & 3 & - \\
\hline
\end{tabular}

Table.2 Comparative Evaluation of biopsy based tests with HPE

\begin{tabular}{|l|l|l|}
\hline & Giemsa-crush cytology & RUT \\
\hline sensitivity & $96.4 \%$ & $94.5 \%$ \\
\hline specificity & $100 \%$ & $96.9 \%$ \\
\hline PPV & $100 \%$ & $96.3 \%$ \\
\hline NPV & $97 \%$ & $95.4 \%$ \\
\hline$\%$ of false positives & $3.6 \%$ & $3.1 \%$ \\
\hline \% of false negatives & nil & $5.4 \%$ \\
\hline Kappa value & 0.96 & 0.92 \\
\hline Interpretation of kappa value & Almost perfect agreement & Almost perfect agreement \\
\hline
\end{tabular}

The in-house rapid urease test was positive in $45 \%(n=54 / 120)$, Giemsa staining of crush cytology in $44.2 \%(\mathrm{n}=53 / 120)$ and Histopathology in $45.8 \%(\mathrm{n}=55 / 120)$.Among the 54 RUT positive samples, $11(20.4 \%)$ turned positive within 1 minute and 36 specimens $(66.7 \%)$ in $1-5$ minutes, 6 specimens $(11.1 \%)$ in 30 minutes. Thus by 10 minutes 53 of 54 samples $(98.1 \%)$ had changed colour.One specimen $(1.8 \%)$ became positive at one hour. The results of rapid urease test,Giemsa stain and RUT were compared to that of histopathology by H\&E stain and are shown in Table1\&2.

A number of cytological techniques have been used to identify H.pylori such as imprint smears, brush cytology and crush cytology. In imprint or touch smears, only the superficial part of the biopsy sample is harvested on the slides while crush smears represent the whole biopsy tissue. The present study found an excellent sensitivity and specificity for Giemsa stained crush cytology with almost perfect agreement with histopathology. Other studies have noted good concordance of $76.5 \%$ between crush cytology and histology (Soltesz et al., 1992).

The rapid urease test is advantageous in that the results are available in the endoscopy room itself. This study observed a good sensitivity and specificity for urease test (94.5\% \& 96.9\% respectively). Other studies have also reported a similar sensitivity and specificity of $94 \%$ and $99 \%$. A higher concentration of urea and omission of buffer in the in-house test induces a more rapid colour change (Working party of the European Helicobacter Study Group, 1997). In our study, $98.1 \%$ of the samples had turned positive by 30 minutes. This is comparable to the study by Thijs in which $94.54 \%$ of the positive rapid urease tests changed colour within 30 minutes (Thijs et al., 1996).

In this study, there were two samples positive by RUT but negative by HPE. These samples showed delayed colour change beyond 5 minutes. The delayed colour change could be due to other urease 
producing bacteria which produce much less urease than H.pylori. Similarly three samples were negative by RUT but histopathologically positive. Such false negative RUTs could be due to the presence of gastric atrophy where in the organisms are low in numbers or absent, or due to patchy distribution of the organisms (Calam, 1996). False negative results due to sampling error are diminished by testing multiple biopsies, discontinuation of antibiotic for at least 1 month and proton pump inhibitors 2 weeks before endoscopy (Working party of the European Helicobacter Study Group, 1997).

The H.pylori status in the study population based on HPE was $45.8 \%$. Other studies have reported prevalence rates varying from $60 \%$ to $100 \%$ in duodenal ulcer and $20 \%$ to $100 \%$ in gastric ulcer (Philip Abraham. Helicobacter pylori, 1997). The prevalence of Helicobacter pylori in gastro duodenal disease during routine upper gastrointestinal endoscopies in South India was reported as $58 \%$ in patients with gastroduodenitis (Thayumanavan, 1997).

In conclusion, this study indicates that Giemsa stained crush cytology is a simple, highly sensitive and specific method for rapid detection of Helicobacter pylori infection .As the result can be made available in the endoscopy room itself , it is more useful for rapid diagnosis of H.pylori in out patients than histopathology.

\section{References}

Barthel, J.S., E.D. Everett. 1990. Diagnosis of Campylobacter pylori infections .The Gold standard and the alternatives. Reviews of infect. Dis., 12(1): S107-14.

Calam, J. 1996. Diagnosis of infection .Clinician's Guide to Helicobacter pylori: $1^{\text {st }}$ ed. (Chapman \& Hall,London) 93-116.

Chiu, W.Y., W.K. Chick, K.H. Kwok. 1999. A home made rapid urease test in the diagnosis of Helicobacter pyloriinfection. Singapore Med. J., 40(4): 243-5.

Lee, J.M., Breslin, N.P., Fallon, C., O’Morain, C.A. 2000. Rapid Urease test lack sensitivity in Helicobacter pylori diagnosis when peptic ulcer disease presents with bleeding. American J. Gastroenterol., 95(5): 1166-70.

Lee, J.Y., Kim, N. 2015. Diagnosis of Helicobacter pylori by invasive test: histology. Ann. Transl. Med., 3(1): 10.

Nijhavan, R., R. Kochchar, D. Panigrahi. 1993. Identification of Helicobacter pylori by Endoscopic Crush Cytology. Indian J. Gastroenterol., 12(2): 45-6.

Philip Abraham. 1997. Helicobacter pylori: a review of practices and research in India .Indian J. Gastroenterol., 16(Suppl 1): S1S2.

Soltesz, V., B. Zeeberg, T. Wadstrom. 1992. Optimal survival of Helicobacter pylori under various transport conditions. J. Clin. Microbiol., 30(6): 1453-6.

Thayumanavan, L. 1997. Prevalence of Helicobacter pylori in gastroduodenal disease during routine upper gastrointestinal endoscopies at Madurai. Indian $J$. Gastroenterol., 16: S35.

Thijs, J.C., A.A. Van Zwet, W.J. Thijs. 1996. Diagnostic tests for Helicobacter pylori: A prospective evaluation of their accuracy without selecting a single test as the gold standard. The American J. Gastroenterol., 91(10): 2125-9.

Working party of the European Helicobacter Study Group. 1990. Guidelines for clinical trials in H.pylori infection. Gut., 41(2): S1S18.

\section{How to cite this article:}

Deepa, R., Sujatha Varadarajan, T.S. Vijayalakshmi and Natesan, B. 2016. A Comparative Evaluation of Microbiological versus Histopathological Diagnostic Methods for Helicobacter pylori Infection. Int.J.Curr.Microbiol.App.Sci. 5(8): 305-308. doi: http://dx.doi.org/10.20546/ijcmas.2016.508.032 